\title{
Ignition of Combustible Fuel Beds by Hot Particles: An Experimental and Theoretical Study
}

\author{
Rory M. Hadden, BRE Center for Fire Safety Engineering, \\ University of Edinburgh, Edinburgh, $U K$ \\ Sarah Scott, Chris Lautenberger and A. Carlos Fernandez-Pello*, \\ Department of Mechanical Engineering, University of California, \\ Berkeley, CA 94720, USA
}

Received: 25 February 2010/Accepted: 17 September 2010

\begin{abstract}
The process of spotting occurs in wildland fires when fire-lofted embers or hot particles land downwind, leading to ignition of new, discrete fires. This common mechanism of wildland fire propagation can result in rapid spread of the fire, potentially causing property damage and increased risk to life safety of both fire fighters and civilians. Despite the increasing frequency and losses in wildland fires, there has been relatively little research on ignition of fuel beds by embers and hot particles. In this work, an experimental and theoretical study of ignition of homogeneous cellulose fuel beds by hot metal particles is undertaken. This type of well-characterized laboratory fuel provides a more controllable fuel bed than natural fuels, and the use of hot metal particles simplifies interpretation of the experiments by reducing uncertainty due to unknown effects of the ember combustion reaction. Spherical steel particles with diameters in the range from $0.8 \mathrm{~mm}$ to $19.1 \mathrm{~mm}$ heated to temperatures between $500^{\circ} \mathrm{C}$ and $1300^{\circ} \mathrm{C}$ are used in the experiments. A relationship between the size of the particle and temperature required for flaming or smoldering ignition is found. These results are used to assess a simplified analysis based on hot-spot ignition theory to determine the particle size-temperature relationship required for ignition of a cellulose fuel bed.
\end{abstract}

Keywords: Ignition, Spotting, Ember, Hot particle, Hot-spot ignition

\section{Nomenclature}

a Surface area

A Pre-exponential factor

$b \quad$ Volumetric heat capacity ratio

c Specific heat capacity

$C_{1} \quad$ Curve fitting constant

$C_{2} \quad$ Curve fitting constant

$E \quad$ Activation energy

$\Delta H \quad$ Heat of combustion

$k \quad$ Thermal conductivity

\footnotetext{
* Correspondence should be addressed to: A. Carlos Fernandez-Pello, E-mail: ferpello@me.berkeley.edu
} 


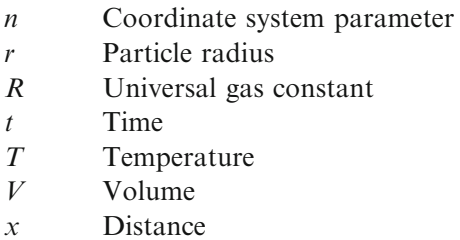

\section{Greek Symbols}

$\beta \quad$ Dimensionless inverse temperature

$\delta \quad$ Frank-Kamenstskii hot spot parameter

$\theta \quad$ Dimensionless temperature

$\rho \quad$ Density

$\xi \quad$ Dimensionless distance

$\tau \quad$ Dimensionless time

\section{Subscripts}

p Particle

$0 \quad$ Initial

\section{Introduction}

Firebrand spotting is a major mechanism for spread of wildland and wildland urban interface (WUI) fires under dry, hot, and windy conditions that produce the most devastating fires. Spotting leads to more rapid fire spread than flame front propagation because embers generated by burning vegetation or structures are lofted by fire plumes and transported downwind to ignite secondary fires or structures remote from the fire front. Similarly, many structures destroyed during WUI fires are not ignited by direct flame impingement, but rather by embers penetrating vents/eaves or direct ignition of roof construction and other "soft" targets. Following the devastating 1994 Sydney wildland fires, a statistical study determined that $75 \%$ of houses were ignited by firebrands, while $25 \%$ were ignited by firebrands and flame radiation [1]. Molten/burning particles can sometimes be generated by high-voltage powerline conductors clashing in high winds. When these hot particles (typically copper or aluminum) reach the ground they may ignite fires in surrounding vegetation. Furthermore, civilians and firefighters alike can become trapped between spot fires with no escape route.

The conditions under which embers and heated particles can ignite a spot fire have not been widely investigated. Only a few studies have examined the critical conditions that can lead to fire initiation after the landing of a firebrand or particle on a particular fuel bed. These studies are primarily experimental in nature [28], and no comprehensive theoretical studies have yet been conducted to analyze the problem or develop generalized predictive tools. Consequently, previous models of wildland fire propagation [9-11] have limited capabilities to predict the initiation of spot fires.

The work presented here is a combined experimental and theoretical study of fuel bed ignition by hot particles. Inert steel spheres are used to approximate 
firebrands/heated particles to remove uncertainty introduced with burning embers (ember temperature, char layer thickness, combustion characteristics, thermal properties, etc.). Similarly, powdered cellulose is used as the target fuel because it is homogeneous in composition and has known properties. Finally, a simplified analytical treatment based on the classical hot spot theory is reviewed and its predictive capabilities are assessed.

\section{Background}

\subsection{Firebrand/Particle Generation and Transport}

The first step of spot fires is the generation of the firebrand. Firebrand generation is the process through which natural fuels are broken into smaller burning pieces during a fire and lofted by a buoyant fire-induced plume or powerlines interact generating molten metal particles. Yoshioka et al. [12] and Manzello et al. [7, 13] have characterized the number and size distribution of brands generated by different fuels. Firebrands generated by a single Douglas Fir can range in size from $\sim 200 \mathrm{~mm}$ to $\sim 10 \mathrm{~mm}$ in diameter.

The trajectories and burning rates of firebrands or heated particles lofted by fires have been studied more extensively [14-23]. Collectively, the studies suggest that small embers or particles are easily lofted and can travel long distances. However, they may burn out or have a low temperature at landing, and are therefore less likely to cause ignition. In comparison, large embers or particles may have long burn times, but they are more difficult to transport and therefore do not travel far from the fire front. Embers or particles of intermediate size have a relatively long burn time and can be lofted considerable distances.

\subsection{Spot Fire Formation: Ignition (or Non-Ignition) of Fuel Beds After Particle Landing}

The aspect of spot fire formation that is least understood is what happens after a firebrand or heated particle lands on a target fuel bed. Of greatest interest is whether or not ignition (smoldering ignition, flaming ignition, or smoldering followed by transition to flaming) occurs. This complex process depends on several factors, including the size and state of the brand or particle (temperature, smoldering/ glowing, flaming), the characteristics of the fuel bed on which it lands (temperature, density, porosity, moisture content), and environmental conditions (temperature, humidity, wind velocity). Ignition of fuel beds by fire brands and heated surfaces has been studied primarily experimentally, in particular by workers at NIST [4-7]. Studies on ignition by metal particles have been reported by Rowntree and Stokes [2,3].

Using single glowing embers of Douglas Fir $(5 \mathrm{~mm}$ or $10 \mathrm{~mm}$ diameter, $51 \mathrm{~mm}$ and $76 \mathrm{~mm}$ length, respectively) under air flow of $0.5 \mathrm{~m} / \mathrm{s}$ or $1 \mathrm{~m} / \mathrm{s}$, Manzello et al. [7] found that smoldering ignition would occur in shredded paper but no ignition would occur in pine needles or hardwoods. For flaming embers under the same conditions, flaming ignition would occur in all fuels except hardwood mulch at $11 \%$ moisture content. Using four glowing embers, smoldering ignition could 
be achieved in dry hardwood mulch. However, four flaming embers were not capable of igniting hardwood at $11 \%$ moisture content. Similar results are found using disk shaped embers $[4,5]$ where flaming ignition occurred only when flaming embers are dropped. It was also observed that multiple flaming embers resulted in flaming ignition where single embers would cause no ignition. In general, smoldering particles are not capable of igniting fuels, whereas flaming embers will likely result in ignition of thin, dry fuels.

Electrically heated hot-spots were used by Caine et al. [8] to study the ignition of four porous fuels. As hot-spot size was increased, the power required to ignite the material was observed to increase which is believed to be explained by the existence of a critical temperature for ignition. No obvious relationship between the hot-spot diameter and the temperature required for ignition in any of the four fuels was found.

These experimental studies differ from the experiments reported in this paper because rather than inert particles, combusting embers or particles artificially maintained at elevated temperatures were used. Therefore, ignition is influenced both by the combustion reaction and heat transfer between the particle and the fuel bed.

A few theoretical studies related to ignition of fuel beds by have been conducted. It has been suggested $[2,3]$ that the energy content (Joules) of a particle can be used as an ignition criterion, analogous to the minimum ignition energy concept for gases. Essentially, if the energy content of a particle is greater than a particular threshold, then ignition occurs. However, Babrauskas [24] has critiqued this approach and justifiably concludes that it is insufficient because particles of different size with the same energy do not necessarily result in ignition. He also notes that laboratory studies to date do not allow the determination of which thermal properties control incendivity. Babrauskas concludes that the "hot spot" ignition theory will allow reasonable prediction of particle size-temperature relationships for ignition. Hot spot theory was originally developed in the 1960s and 1970s [2529] and applied later [30-32] to ignition of natural fuels. More recently, detailed numerical models have been applied to simulate spot fire initiation [33-35].

\section{Experiment Description}

The experimental apparatus used in this work is shown in Figure 1. Spherical steel particles of diameter $0.8 \mathrm{~mm}, 1.6 \mathrm{~mm}, 2.4 \mathrm{~mm}, 3.2 \mathrm{~mm}, 4.4 \mathrm{~mm}, 6.2 \mathrm{~mm}, 9.5 \mathrm{~mm}$, $12.7 \mathrm{~mm}, 15.9 \mathrm{~mm}$, and $19.1 \mathrm{~mm}$ heated to temperatures between $500^{\circ} \mathrm{C}$ and $1300^{\circ} \mathrm{C}$ were used. The fuel bed is mounted in a wind tunnel with the sample surface flush with bottom of the tunnel. The wind-tunnel is $550 \mathrm{~mm}$ in length with a $130 \mathrm{~mm}$ by $80 \mathrm{~mm}$ cross section. The sample holder is $150 \mathrm{~mm}$ long, $100 \mathrm{~mm}$ wide and $50 \mathrm{~mm}$ deep and its leading edge is $150 \mathrm{~mm}$ from the inlet of the tunnel. The target fuel was approximately $130 \mathrm{~g}$ of dry, fine powdered $\alpha$-cellulose placed, uncompacted, in the sample holder. In order to ensure uniform properties throughout, the mass of cellulose used for each experiment was weighed before testing to ensure the bulk porosity remained constant at $\sim 200 \mathrm{~kg} / \mathrm{m}^{3}$. Compressed house air is introduced to the wind tunnel at a velocity of $0.5 \mathrm{~m} / \mathrm{s}$. Sheathed $\mathrm{K}$-type thermocouples are inserted into the fuel sample at locations shown in 


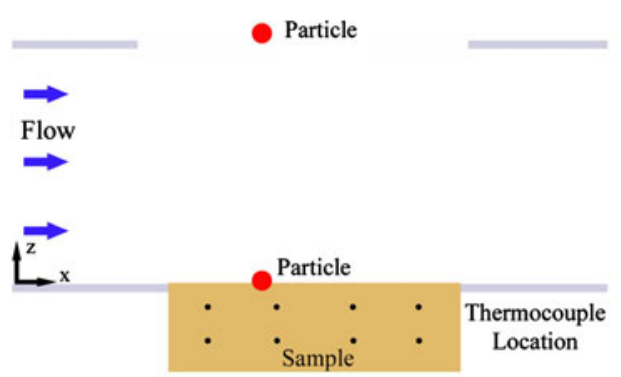

(a)

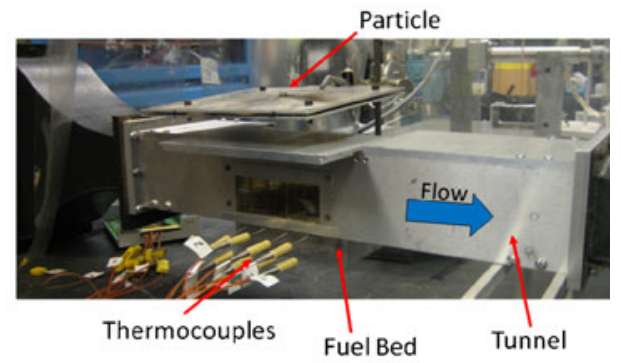

(b)

\section{Figure 1. a Simplified schematic and b photograph of experimental apparatus.}

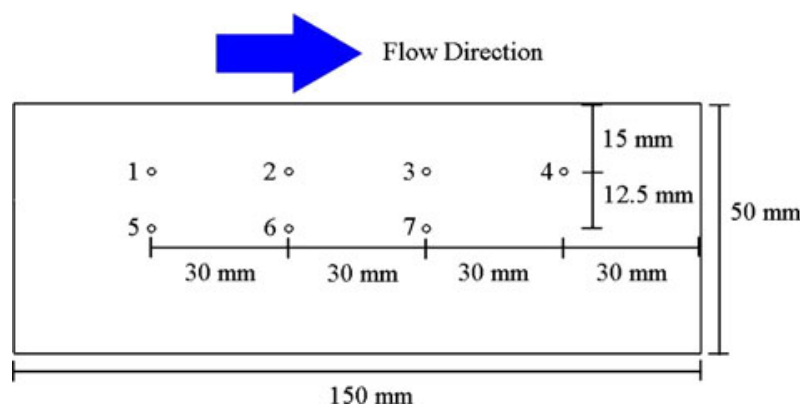

Figure 2. Fuel bed dimensions and thermocouple locations.

Figure 2. Glass panels allow for observation and video recording of the test. Only solid phase temperatures are measured in this set-up. There is a removable section in the roof of the tunnel to allow hot particles to be dropped on the sample.

During an experiment, a particle of desired size is heated with a premixed propane flame. Once the particle has reached the desired temperature, as measured by a thermocouple inserted into the particle, it is dropped onto the sample surface from a height of approximately $20 \mathrm{~mm}$. The particle is dropped approximately $35 \mathrm{~mm}$ downstream from the leading edge of the sample. Fuel bed temperature is recorded along the centerline at seven locations as shown in Figure 2.

The depth to which the hot spheres penetrated the fuel bed was not controlled and was found to vary depending on the size of the sphere. Large spheres were more likely to be partially embedded while smaller particles could be completely embedded. The depth of the particle below the surface is likely to have an effect on ignition, but this was not studied in this work.

\section{Experimental Results}

Experiments are conducted to identify the effect of particle size and temperature on ignition of powdered cellulose. Depending on the particle characteristics, both 
flaming and smoldering ignition were observed. In flaming ignition, a flame kernel initiated around the hot particle; if the particle was hot enough, this flame would propagate across the free surface of the sample and eventually extinguish. Indepth smoldering would then be seen to continue for several hours.

In the case of smoldering ignition, a smolder front would be established around the hot particle. This front would then propagate laterally as well as in depth. In all cases when smoldering was ignited, the sample was seen to burn to completion. Transition from smoldering to flaming was not observed.

\subsection{Temperature Profiles}

Figure 3 shows the temperature profile for a sample in which flaming occurred initially across the surface of the sample followed by in depth smoldering. Peak fuel bed temperatures are in the range from $465^{\circ} \mathrm{C}$ to $550^{\circ} \mathrm{C}$. Temperatures in depth were higher than those closer to the free surface due to heat losses. The temperature peak in the solid phase advances both laterally and in depth from the point where the hot particle was dropped.

\subsection{Smolder Spread Rate}

The smolder spread rate of the solid phase reactions was found to be a function of depth and distance from the hot particle. Spread rate was calculated by finding the times at which each thermocouple reached $300^{\circ} \mathrm{C}$ and dividing the distance between the thermocouples by the time between adjacent thermocouples reaching this temperature.

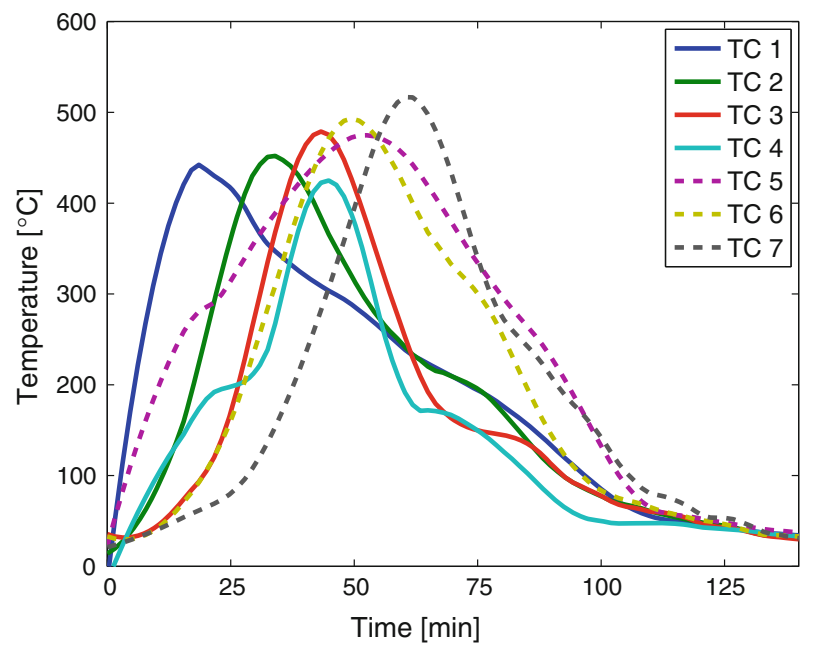

Figure 3. Temperature profiles in the fuel bed for a sample in which flaming was observed. Thermocouple locations refer to those in Figure 2. 
For the example above, at a depth of $15 \mathrm{~mm}$ below the free surface, spread rates were $2.0 \mathrm{~mm} / \mathrm{min}, 3.1 \mathrm{~mm} / \mathrm{min}$ and $5.3 \mathrm{~mm} / \mathrm{min}$ at positions between $30 \mathrm{~mm}$ and $60 \mathrm{~mm}, 60 \mathrm{~mm}$ and $90 \mathrm{~mm}$, and $90 \mathrm{~mm}$ and $120 \mathrm{~mm}$ from the leading edge, respectively. This suggests that as the size of the reaction front grows, the spread rate increases. However, at a depth of $17.5 \mathrm{~mm}$ below the free surface, this effect is much reduced and the spread rates are $2.9 \mathrm{~mm} / \mathrm{min}$ and $2.7 \mathrm{~mm} / \mathrm{min}$ between thermocouple locations $30 \mathrm{~mm}$ and $60 \mathrm{~mm}$ and $60 \mathrm{~mm}$ and $90 \mathrm{~mm}$ from the leading edge, respectively. These spread rates are in agreement with others reported in the literature [36].

\subsection{Propensity for Ignition}

Figure 4 shows the ignition propensity as a function of particle size and temperature. Triangles represent direct flaming ignition, circles are smoldering ignition, and crosses represent no ignition. The data clearly show a demarcation between no ignition, smoldering ignition, and flaming ignition. It can be seen that for both flaming and smoldering ignition, smaller particles require higher temperatures than larger particles. The trends in Figure 4 are qualitatively consistent with the data of Stokes and Rowntree [2,3]. Due to the experimental method for delivering the hot particles, it was not always possible to ensure the particles were exactly the same temperature upon landing on the fuel and obtained the same level of submergence in the cellulose. This results in some overlap between the ignition types in some cases.

Figure 4 contains two lines that demarcate the regions of flaming and smoldering ignition. These lines are of the form:

$$
2 r_{p}=C_{1} T_{p} \sqrt{\left(\exp \left(\frac{C_{2}}{T_{p}}\right)\right)}
$$

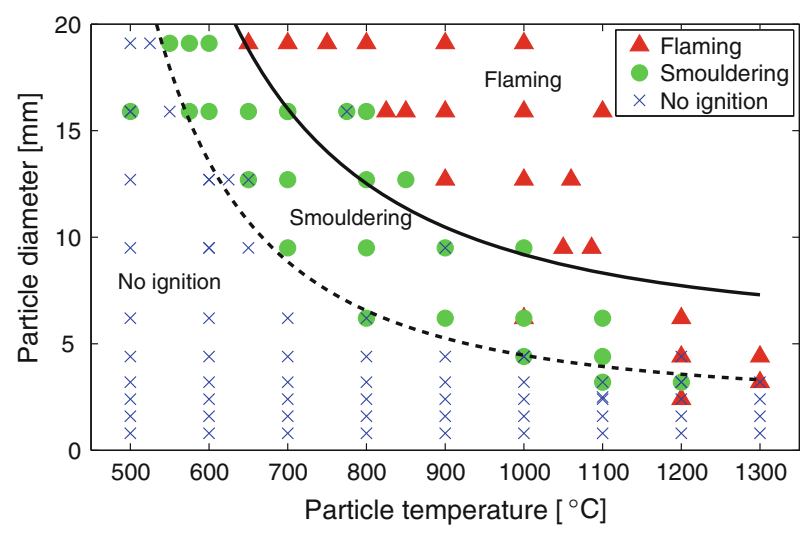

Figure 4. Ignition propensity of dry cellulose using heated steel spheres. 


\section{Table 1}

Values of Constants for Demarcation of Ignition Regimes

\begin{tabular}{lcc}
\hline & $C_{1}[\mathrm{~m} / \mathrm{K}]$ & $C_{2}[\mathrm{~K}]$ \\
\hline Smoldering & 0.0004 & 4862 \\
Flaming & 0.0011 & 4264 \\
\hline
\end{tabular}

where $C_{1}$ and $C_{2}$ were selected to fit the data. The functional form of Eq. 1 is based on the hot spot theory discussed in Sect. 5.1 (see Eq. 21) (Table 1).

For the range of particles tested, the minimum particle temperature at which smoldering could be initiated was $550^{\circ} \mathrm{C}$, and the minimum temperature at which flaming ignition occurred was $650^{\circ} \mathrm{C}$. In both cases, this was for a particle diameter of $19.1 \mathrm{~mm}$. Flaming could only be observed for particles larger than $2.4 \mathrm{~mm}$ heated to $1200^{\circ} \mathrm{C}$.

Figure 5 shows energy plotted against particle size where energy is calculated using the specific enthalpy for a given particle temperature and mass of the sphere. It can be seen that a correlation between particle energy and ignition is not sufficient to explain the observed results. For example, an energy of $200 \mathrm{~J}$ will result in flaming ignition for particles $9.5 \mathrm{~mm}$ and $12.7 \mathrm{~mm}$ but only smoldering ignition for particles of $15.9 \mathrm{~mm}$ and $19.1 \mathrm{~mm}$. This suggests that the ignition process is complex and governed not only by the energy of an ember but also the temperature and size in agreement with the comments by Babrauskas [24].

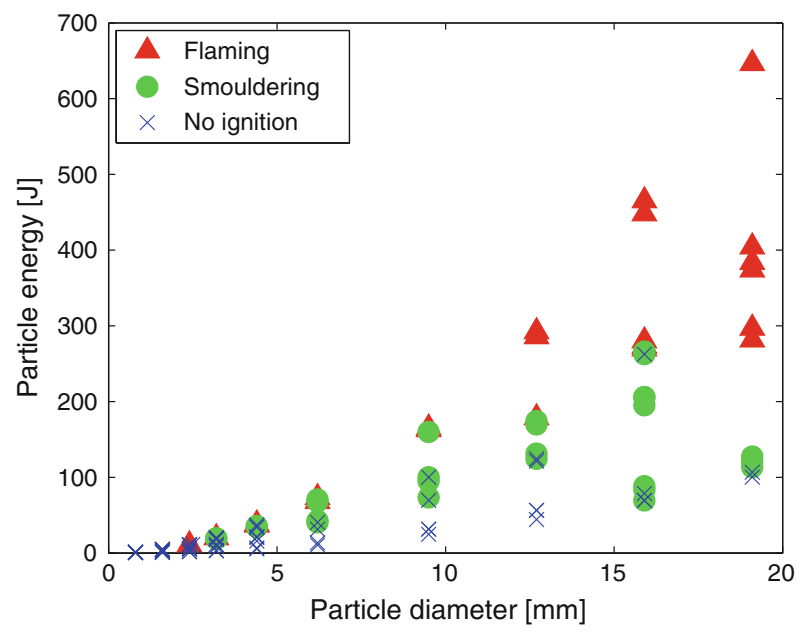

Figure 5. Particle energy versus particle size. Showing flaming ignition (triangles), smodlering ignition (circles) and no ignition (crosses). 


\section{Simplified Theoretical Analysis}

\subsection{Hot Spot Theory}

It has been suggested that hot spot theory [24-28] can be used to model the ignition of natural fuels by heated particles. In a sequence of three papers, Jones [3032] applied hot spot theory to simulate the ignition of forest litter by copper particles. In [32], the theory of Gol'dshleger et al. [25] is applied. This theory [25] has been recommended by Bowes [37] for its compromise between accuracy and tractability, and has also been applied by Babrauskas [24] to model the barley grass ignition experiments of Rowntree and Stokes [3] involving heated particles. Since the hot spot theory of Gol'dshleger et al. [25] seems to be a logical starting point for modeling the present experiments, it is presented briefly below and then applied to the current experiments.

The governing equations for a non-reactive hot spot particle (subscript $p$ ) completely embedded in an infinite target fuel are as follows:

$$
\begin{aligned}
& \text { for } 0<x<r: \quad \rho_{p} c_{p} \frac{d T_{p}}{d t}=\left.\frac{a_{p}}{V_{p}} k \nabla T\right|_{x=r^{+}} \\
& \text {for } r \leq x<\infty: \quad \rho c \frac{\partial T}{\partial T}=\nabla \cdot k \nabla T+\rho A \Delta H \exp \left(-\frac{E}{R T}\right)
\end{aligned}
$$

In writing Eq. 2, the energy equation for the particle, it has been assumed that $k_{p} \gg k$ (i.e., the particle temperature is uniform due to its high thermal conductivity) and that the particle is in good thermal contact with the surrounding fuel bed so that the rate of heat transfer from the particle is $a_{p} k \nabla T$ where $a_{p}$ is the particle surface area.

The initial conditions for the particle and the target fuel are:

$$
\begin{array}{ll}
\text { for } 0<x<r: & \left.T_{p}\right|_{t=0}=T_{p 0} \\
\text { for } r \leq x<\infty: & \left.T\right|_{t=0}=T_{0}
\end{array}
$$

The boundary conditions on Eq. 3 are:

$$
\begin{aligned}
& \left.T\right|_{x \rightarrow \infty}=T_{0} \\
& \left.T\right|_{x=r^{+}}=T_{p}
\end{aligned}
$$

Equations 2-7 are nondimensionalized by introducing dimensionless temperature, distance, and time variables:

$$
\theta=\frac{E}{R T_{p^{0}}^{2}}\left(T-T_{p 0}\right)
$$




$$
\begin{aligned}
\xi & =\frac{x}{r} \\
\tau & =\frac{t}{\frac{c R T_{p^{0}}^{2}}{A E \Delta H \exp \left(-E / R T_{p 0}\right)}}
\end{aligned}
$$

Three additional dimensionless parameters $(\delta$, the Frank-Kamenetskii hot spot parameter; $b$ the volumetric heat capacity ratio; and $\beta$, the dimensionless inverse particle temperature) are defined as follows:

$$
\begin{aligned}
\delta & =r \sqrt{\frac{\rho A \Delta H}{k} \frac{E}{R T_{p 0}^{2}} \exp \left(-\frac{E}{R T_{p 0}}\right)} \\
b & =\frac{\rho c}{\rho_{p} c_{p}} \\
\beta & =\frac{R T_{p 0}}{E}
\end{aligned}
$$

The one-dimensional constant-property governing equations (i.e., the 1D dimensionless counterparts to Eqs. 2 and 3) for the particle and target fuel bed become:

$$
\begin{aligned}
& \frac{d \theta_{p}}{d \tau}=\left.\frac{n+1}{\delta^{2}} b \frac{\partial \theta}{\partial \xi}\right|_{\xi=1^{+}} \\
& \frac{d \theta}{\partial \tau}=\frac{1}{\delta^{2}}\left(\frac{\partial^{2} \theta}{\partial \xi^{2}}+\frac{n}{\xi} \frac{\partial \theta}{\partial \xi}\right)+\exp \left(\frac{\theta}{1+\beta \theta}\right)
\end{aligned}
$$

where $n$ is the coordinate system parameter $(n=0$ for Cartesian coordinates, $n=1$ for cylindrical coordinates, and $n=2$ for spherical coordinates).

The initial conditions are:

$$
\begin{aligned}
& \text { for } 0<\xi<1:\left.\quad \theta_{p}\right|_{\tau=0}=\theta_{p 0}=0 \\
& \text { for } 1 \leq \xi<\infty:\left.\quad \theta\right|_{\tau=0}=\theta_{0}=-\theta_{\Delta}
\end{aligned}
$$

The boundary conditions on Eq. 15 are:

$$
\begin{aligned}
& \left.\theta\right|_{\xi=1^{+}}=\theta_{p} \\
& \left.\theta\right|_{\xi \rightarrow \infty}=\theta_{0}
\end{aligned}
$$

Equations 14-19 cannot be solved exactly, and numerical solution is required. Of primary interest is the value of the $\delta$ at which thermal runaway (ignition) occurs 
$\left(\delta_{\text {cr }}\right)$. It should be noted that Equations 2-7 do not include heat losses from the system as a whole since it is assumed to be infinite. In a mathematical sense, thermal runaway may occur at long time scales for certain parameter values even without a hot spot. However, here we consider ignition to be thermal runaway that occurs at a time scale that is much shorter than that associated with the adiabatic induction period. Gol'dshleger et al. [25] conducted numerical simulations to determine the value of $\delta_{\text {cr }}$ and found that the following curve-fit matched their numerical results within $10 \%$ :

$$
\delta_{\text {cr }} \approx 0.4 \sqrt{b^{2}+0.25 n(n+1)\left(b+0.1 b^{3}\right)}\left(2.25(n-1)-\theta_{0}\right)^{2}\left(1-0.5 \beta \theta_{0}\right)
$$

Once $\delta_{\text {cr }}$ is calculated from Eq. 20, the critical hot spot radius $r_{\text {cr }}$ (i.e., the minimum particle radius for ignition) can be calculated from the definition of $\delta$ (Eq. 11) as:

$$
r_{\mathrm{cr}}=\delta_{\mathrm{cr}} \sqrt{\frac{k}{\rho A \Delta H} \frac{R T_{p 0}^{2}}{E} \exp \left(\frac{E}{R T_{p 0}}\right)}
$$

\subsection{Application to Present Experiments}

Thermophysical properties of cellulose and the particle are necessary to calculate the critical radius size for ignition. The thermophysical properties used in this analysis are given in Table 2 .

Figure 6 compares the critical particle diameter for ignition calculated via Eq. 21 with experimental data.

\subsection{Assessment of Hot Spot Theory Predictive Capabilities for Present Experiment}

It can be seen from Figure 6 that the hot spot theory presented above, when provided with the input parameters given in Table 2, qualitatively reproduces the experimental data but is not quantitatively accurate. However, the hot spot theory is conservative for particles smaller than $\sim 2.4 \mathrm{~mm}$ in diameter that have temperatures greater than $850^{\circ} \mathrm{C}$ because it suggests that ignition occurs for some size/ temperature combinations but the experiments show that ignition does not occur.

Some aspects of the present experiments not included in the hot spot theory include:

1. The mechanism of flaming ignition may be somewhat different from that described by hot spot theory (thermal runaway inside the condensed phase). It is possible that a heated particle sitting on top of the cellulose bed acts as a localized heat source, causing the powdered cellulose to pyrolyze at a rate that is sufficient to produce a flammable mixture in the vicinity of the heated particle, which in turn acts as an ignition pilot. Gas-phase ignition (outside of the 


\section{Table 2}

Thermophysical Properties of Target Fuel Bed (Cellulose) and Heated Particle (Steel)

\begin{tabular}{lllll}
\hline Parameter & Value & Units & Reference & Description \\
\hline$k$ & 0.1 & $\mathrm{~W} / \mathrm{m} \cdot \mathrm{K}$ & Estimated & Thermal conductivity (target) \\
$\rho$ & 200 & $\mathrm{~kg} / \mathrm{m}^{3}$ & Measured & Density (target) \\
$c$ & 2.0 & $\mathrm{~kJ} / \mathrm{kg} \cdot \mathrm{k}$ & Estimated & Specific heat capacity (target) \\
$\rho_{p}$ & 7833 & $\mathrm{~kg} / \mathrm{m}^{3}$ & {$[38]$} & Density (particle) \\
$c_{p}$ & 465 & $\mathrm{~J} / \mathrm{kg} \cdot \mathrm{K}$ & {$[38]$} & Specific heat capacity (particle) \\
$A$ & $1 \times 10^{17 \mathrm{a}}$ & $\mathrm{s}^{-1}$ & {$[39]$} & Pre-exponential factor \\
$E$ & $222^{\mathrm{a}}$ & $\mathrm{kJ} / \mathrm{mol}$ & {$[39]$} & Activation energy \\
$\Delta H$ & $10^{\mathrm{b}}$ & $\mathrm{MJ} / \mathrm{kg}$ & {$[40]$} & Heat of combustion \\
$T_{0}$ & 300 & $\mathrm{~K}$ & Measured & Initial temperature \\
\hline
\end{tabular}

\footnotetext{
${ }^{\text {a }}$ Average from eight TGA experiments at $40^{\circ} \mathrm{C} / \mathrm{min}$ heating rate.

${ }^{b}$ The heat of complete combustion of cellulose is approximately $15 \mathrm{MJ} / \mathrm{kg}$ [40] but since $\mathrm{CO}$ is expected to form in considerable amounts, the heat of combustion is reduced by $1 / 3 \mathrm{MJ} / \mathrm{kg}$ to $10 \mathrm{MJ} / \mathrm{kg}$.
}

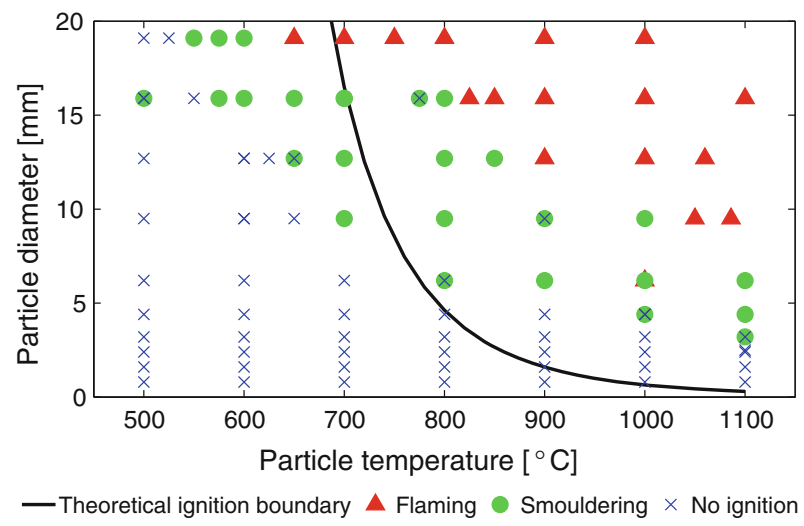

\section{Figure 6. Comparison of experimental data with hot spot theory (Eq. 21 ) using the parameters in Table 2.}

fuel bed) may occur if the residence time of the combustible gas mixture flowing by the heated particle is comparable to the ignition delay time of that mixture at the particle temperature. Ignition would occur in the gas-phase, and a diffusion flame then becomes anchored to the surface.

2. Hot spot theory assumes the particle is completely embedded in an infinite medium, but in the experiments the heated particles sit on top of or are partially embedded in the fuel bed.

3. Surface heat losses are not accounted for. The particle loses heat by convection and radiation to the ambient and this effect is not included in the simplified analysis. 
4. Oxygen availability is not accounted for. Equations 3 and 15 have an exothermic source term on the right hand side. Thus, these equations inherently assume that the pore space contains sufficient oxygen to drive an exothermic oxidative reaction. However, if oxygen inside the pore space is completely consumed, then thermal decomposition of cellulose is likely endothermic.

5. The above analysis assumes that consumption of reactants is negligible (zeroth order Arrhenius reaction) but reactant consumption may not be negligible.

6. The above analysis assumes that a single reaction occurs whereas in actuality multiple reactions may occur.

7. Hot spot theory does not account for any effects of volume change such as shrinkage, swelling, or compaction of the fuel bed by particles.

\section{Concluding Remarks}

Ignition of cellulose fuel beds by hot spherical particles has been studied experimentally and a model of hot spot ignition presented.

- The results show as particle size is reduced, increased temperature is required for ignition. For a particle size of $2.4 \mathrm{~mm}$, temperatures of $1200^{\circ} \mathrm{C}$ were required for flaming ignition and this was reduced to $650^{\circ} \mathrm{C}$ for particles of $19.1 \mathrm{~mm}$.

- Ignition propensity is a function of both particle size and particle temperature.

- There is not a unique correlation between particle energy and ignition propensity.

- Hot spot ignition theory provides qualitative agreement with experimental results but is not quantitatively predictive for the present experiments.

\section{Acknowledgments}

Thanks go to the Royal Society of Edinburgh, International Fire Investigators and Consultants Ltd and Engineering and Physical Research Council (UK) for providing the financial assistance for the first author's (RH) work. Part of this work was supported by the University of California, Berkeley.

\section{Open Access}

This article is distributed under the terms of the Creative Commons Attribution Noncommercial License which permits any noncommercial use, distribution, and reproduction in any medium, provided the original author(s) and source are credited.

\section{References}

1. Ramsey GC, McArthur NA (1995) Building in the urban interface: lessons from the January 1994 Sydney bushfires. In: Bushfires 1995, Hobart, Tasmania 
2. Stokes AD (1990) Fire ignition by copper particles of controlled size. J Electr Electron Eng Aust 10:188-194

3. Rowntree GWG, Stokes AD (1994) Fire ignition by aluminum particles of controlled size. J Electr Electron Eng Aust 14:117-123

4. Manzello SL, Cleary TG, Shields JR, Yang JC (2006) On the ignition of fuel beds by firebrands. Fire Mater 30:77-87

5. Manzello SL, Cleary TG, Shields JR, Yang JC (2006) Ignition of mulch and grasses by firebrands in wildland-urban interface fires. Int J Wildland Fire 15:427-431

6. Pitts W (2007) Ignition of cellulosic fuels by heated and radiative surfaces. NIST technical note 1481

7. Manzello SL, Cleary TG, Shields JR, Maranghides A, Mell W, Yang JC (2008) Experimental investigation of firebrands: generation and ignition of fuel beds. Fire Saf $\mathbf{J}$ 43:226-233

8. Caine P, Puttick SJ, Brindley J, McIntosh AC, Griffiths JF (2009) Ignition of bulk solid materials by a localised hotspot. In: Hazards XXI, symposium series no. 155, pp 191-200

9. Finney MA (1998) FARSITE: fire area simulator-model development and evaluation. US Department of Agriculture, Forest Service, Rocky Mountain Research Station, Research Paper RMRS-RP-4, Ogden, UT

10. Linn R, Resiner J, Colman JJ, Winterkamp J (2002) Studying wildfire behavior using FIRETEC. Int J Wildland Fire 11:233-246

11. Mell W, Jenkins MA, Gould J, Cheney C (2007) A physics-based approach to modeling grassland fires. Int J Wildland Fire 16:1-22

12. Yoshioka H, Hayashi Y, Masuda H, Noguchi T (2004) Real-scale fire wind tunnel experiment on generation of firebrands from a house on fire. Fire Sci Technol 23:142150

13. Manzello SL, Shields JR, Cleary TG, Maranghides A, Mell WE, Yang JC, Hayashi Y, Nii D, Kurita T (2008) On the development and characterization of a firebrand generator. Fire Saf J (to appear)

14. Tarifa CS, del Notario PP, Moreno FG (1965) On the flight paths and lifetimes of burning particles of wood. Proc Combust Inst 10:1021-1037

15. Lee SL, Hellman JM (1970) Firebrand trajectory study using an empirical velocitydependent burning law. Combust Flame 15:265-274

16. Albini FA (1979) Spot fire distance from burning trees: a predictive model. GTR-INT56, USDA Forest Service

17. Albini FA (1983) Potential spotting distance from wind-driven surface fires. USDA Forest Service Research Paper ZNT-309

18. Tse SD, Fernandez-Pello AC (1998) On the flight paths of metal particles and embers generated by power lines in high winds - a potential source of wildland fires. Fire Saf $\mathbf{J}$ 30:333-356

19. Woycheese JP (2001) Wooden disk combustion for spot fire spread. In: Interflam 2001, pp 101-112

20. Himoto K, Tanaka T (2005) Transport of disk-shaped firebrands in a turbulent boundary layer. In: Fire safety science. Proceedings of the 8 th international symposium, pp 433-444

21. Anthenien RA, Tse SD, Fernandez-Pello AC (2006) On the trajectories of embers initially elevated or lofted by small scale ground fire plumes in high winds. Fire Saf $\mathbf{J}$ 41:349-363 
22. Sardoy N, Consalvi J-L, Poterie B, Loraud J-C, Fernandez-Pello C (2007) Modeling transport and combustion of firebrands from burning trees. Combust Flame 150:151169

23. Koo E, Pagni P, Linn R (2007) Using FIRETEC to describe firebrand behavior in wildfires. In: Fire and materials 2007, San Francisco, CA

24. Babrauskas V (2003) Ignition handbook: principles and applications to fire safety engineering, fire investigation, risk management, and forensic science. Fire Science Publishers, Issaquah, p. 843

25. Gol'dshleger UI, Pribytkova KV, Barzykin VV (1973) Ignition of a condensed explosive by a hot object of finite dimensions. Fizika Goreniya I Vzryva 9:119-123

26. Zinn J (1949) Initiation of explosions by hot spot. J Chem Phys $36: 7$

27. Boddington $T$ (1963) The growth and decay of hot spots and the relation between structure and stability. Proc Combust Inst 9:287-293

28. Friedman MH (1963) A correlation of impact sensitivities by means of the hot spot model. Proc Combust Inst 9:294-302

29. Thomas PH (1965) A comparison of some hot spot theories. Proc Combust Inst 10:369-372

30. Jones JC (1993) Predictive calculations of the effect of an accidental heat source on a bed of forest litter. J Fire Sci 11:80-86

31. Jones JC (1994) Further calculations concerning the accidental supply of heat to a bed of forest material. J Fire Sci 12:502-505

32. Jones JC (1995) Improved calculations concerning the ignition of forest litter by hot particle ingress. J Fire Sci 13:350-356

33. Zvyagils'kaya AI, Subbotin AN (1996) Influence of moisture content and heat and mass exchange with the surrounding medium on the critical conditions of initiation of surface fire. Combust Explos Shock Waves 32:558-564

34. Grishin AM, Dolgov AA, Zima VP, Kryuchkov DA, Reino VV, Subbottan AN, Tsvyk RS (1998) Ignition of a layer of combustible forest materials. Combust Explos Shock Waves 34:613-620

35. Lautenberger C, Fernandez-Pello AC (2008) Modeling ignition of combustible fuel beds by embers and heated particles. In: Forest fires 2008

36. Rein G (2009) Smoldering combustion phenomena in science and technology. Int Rev Chem Eng 1:3-18

37. Bowes PC (1984) Self heating: evaluating and controlling the hazards. Elsevier, New York

38. The SFPE Handbook of Fire Protection Engineering, 2nd edn (1995) National Fire Protection Association, Quincy, Table B-6

39. Grønli M, Antal MJ, Va'rhegyi G (1999) A round-robin study of cellulose pyrolysis kinetics by thermogravimetry. Ind Eng Chem Res 38:2238-2244

40. Chen Y, Frendi A, Tewari S, Sibulkin M (1991) Combustion properties of pure and fire-retarded cellulose. Combust Flame 84:121-140 